\title{
10. Çocuklara yabancı dil olarak Türkçe öğretiminde hikâye kullanımı
}

\section{Emine KURT'}

APA: Kurt, E. (2021). Çocuklara yabancı dil olarak Türkçe öğretiminde hikâye kullanımı. RumeliDE Dil ve Edebiyat Araştırmaları Dergisi, (23), 144-152. DOI: 10.2900o/rumelide.949162.

\section{$\ddot{\mathbf{O} z}$}

Çocuklara yabancı dil olarak Türkçe öğretimi artan ihtiyaçla birlikte hızla gelişen bir alandır. Türkiye'nin ve dünyanın değişik yerlerinde yabancı dil olarak Türkçe öğrenen çocuklara yönelik materyaller ise sınırlıdır. Çocuklarla çalışmanın doğası gereği onlara çeşitli ve eğlenceli materyaller sunmak önemlidir. Ders kitaplarının dışında hikâye kitapları ve hikâyeler çocukların ana dillerinden de aşina oldukları çok yönlü içerikler olarak ön plana çıkar. Ancak çocuklara yabancı dil olarak Türkçe öğretiminde çalışan eğitimcilere bu materyallerin nasıl seçilip kullanılacağına dair gereken altyapıyı sunacak çalışmalar sınırlıdır. Türkçe alan yazında bu konuda yapılan çalışmaların azlığı dikkat çekmektedir. Oysa yabancı alan yazında çocuklara dil öğretiminde hikâye kullanımı kendisine yer bulmuştur. Çalışmanın temel amacı, çocuklara yabancı dil olarak Türkçeyi eğlenceli ve anlamlı bir şekilde öğretmek için hikâyelerin nasıl kullanılabileceğine dair teorik altyapıyı sağlamaktır. Bu çalışmada çocuklara yabancı dil olarak Türkçe öğretilen sınıflarda hikâyelerin pedagojik değerine vurgu yapılmaktadır. Çocukların ilgi alanlarına ve beğenilerine uygun hikâyeleri seçmek, dili hikâyeler bağlamında öğretmek, Türkçe öğrenmeyi çocuklar için eğlenceli ve yaşam boyu sürecek bir etkinlik haline getirmek nasıl mümkün olabilir sorusunun cevabı aranmıştır. Bu sayede sahada çalışan akademisyenlere, çocuklarla çalışan eğitimcilere ve öğretim materyali hazırlayanlara ihtiyaç duydukları kuramsal desteğin sunulması amaçlanmaktadır. Çalışmada çocuklara yabancı dil olarak Türkçe öğretilen sınıflarda hikâye kullanımı, eğer dersler iyi organize edilirse ve öğretmen gereken hazırlıkları yaparsa öğrencinin dile dair merakını ve dersin başarısını artırmaya katkı sağlayabildiği sonucuna ulaşılmıştır. Çalışmada nitel araştırma yöntemlerine dayalı literatür taraması temelli derleme çalışması yapılmıştır.

Anahtar kelimeler: Çocuklara yabancı dil olarak Türkçe öğretimi, hikâye, okuma becerisi

\section{The use of story in teaching Turkish as a foreign language to children}

\begin{abstract}
Teaching Turkish as a foreign language to children is a field that develops rapidly with the increasing need. Turkish learning materials for children are limited in Turkey and different places in the world. Due to the nature of working with children, it is important to offer them diverse and entertaining materials. Apart from textbooks, story books and stories stand out as versatile content that children are familiar with from their mother tongue. However, there are limited studies that will provide educators working in teaching Turkish as a foreign language to children with the necessary infrastructure on how to select and use these materials. The scarcity of studies on this subject in the Turkish literature draws attention. However, the use of stories in teaching children language has found its way into the foreign literature. The main purpose of the study is to provide
\end{abstract}

Dr. Öğr. Gör., Çukurova Üniversitesi, Rektörlük Türk Dili Bölümü (Adana, Türkiye), eminevekurt@gmail.com, ORCID ID: 00oo-0oo1-5917-4265 [Araştırma makalesi, Makale kayıt tarihi: 01.05.2021-kabul tarihi: 20.06.2021; DOI: 10.29000/rumelide.949162]

RumeliDE Dil ve Edebiyat Araşttrmaları Dergisi Osmanağa Mahallesi, Mürver Çiçeği Sokak, No:14/8 Kadıköy - ÍSTANBUL / TÜRKIYE 34714 e-posta: editor@rumelide.com tel: +90 $5057958124,+902167730616$
Address

RumeliDE Journal of Language and Literature Studies

Osmanağa Mahallesi, Mürver Çiçeği Sokak, No:14/8

Kadıköy - ISTANBUL / TURKEY 34714

e-mail: editor@rumelide.com,

phone: +90 5057958124 , +90 2167730616 


\begin{abstract}
the theoretical background on how stories can be used to teach children Turkish as a foreign language in an entertaining and meaningful way. In this study, the pedagogical value of the stories in the classes where children are taught Turkish as a foreign language is emphasized. The answer to the question of how it is possible to choose stories suitable for the interests and tastes of children, to teach the language in the context of stories, and to make learning Turkish an enjoyable and lifelong activity for children was sought. In this way, it is aimed to provide theoretical support to academicians working in the field, educators working with children and those who prepare teaching materials. In the study, it was concluded that the use of stories in classrooms where Turkish is taught to children as a foreign language can contribute to increasing the student's curiosity about language and the success of the lesson, if the lessons are well organized and the teacher makes the necessary preparations. This is a compilation study based on literature review.
\end{abstract}

Keywords: Teaching Turkish as a foreign language to children, story, reading skill

\title{
Giriş
}

Yabancı dil öğretiminin belirli ilkeler ışığında yapılması gerektiğini vurgulayan Barın (2004, s.29) yabancı dil olarak Türkçe öğretiminde destekleyici hikâye kitaplarının önemine dikkat çekerek dünyada önde gelen kurumların öğrenci düzeylerini gözeten bu tip kitapları yayımladı̆̆ını belirtir. Türkçenin yabancı dil olarak öğretiminde de alan uzmanları tarafından bu konuda çalışmalar yapılması gereğini belirtir. Bu bağlamda çocuklara yabancı dil olarak Türkçe öğretiminde göz önünde bulundurulması gereken ilkelere bakıldığında hikâye kullanımının gerekliliği ortaya çıkar. Kurt (2020, s. 138) çocuklara yabancı dil olarak Türkçe öğretiminin ilkelerini sıralarken bütüncül bir dil öğretimi yapılması, görsellerin sıklıkla kullanılması, çocukların merak duygusunu canlı tutacak etkinliklere yer verilmesi gibi noktaları vurgular. Anlamlı ve eğlenceli edebî ürünler olan hikâyeler çocuklara yabancı dil olarak Türkçe öğretilen sınıflarda kendisine yer bulabilir.

Edebî ürünlerin dil gelişimine katkısı araştırmacılarca sıklıkla vurgulanmaktadır. Ana dili edinirken yaşamının ilk birkaç yılında zengin dil girdisine sahip olmak belirleyicidir. Öte yandan ikinci dil ediniminde de çocuk edebiyatı ürünleri yararlı bulunmaktadır. Çocuk edebiyatı ürünlerinin yabancı dil öğretiminde kullanımı erken dönem dil eğitimcisi Marcus Fabius Quintilian (M.S. 35-95)'a kadar götürülebilir. Bu dönemde Latinceyi yabancı dil olarak öğretmek için kullanılan metodolojide bir Ezop masalı yüksek sesle öğretmen tarafından okunur; daha sonra öğrenciden masalı kendi sözleriyle anlatması istenir. Tarihî süreçte edebî metinlerin kullanılma biçimleri gelişmiştir. Çocuk edebiyatı ürünlerine bu açıdan bakıldığında çocuk hikâyeleri temelde karakter tanıtımı, hedef, problem, çatışma ve çözüm sırasını izler. Daha büyük yaş grupları için hikâyeler biraz daha karmaşıklaşabilir. Bu bağlamda kaliteli çocuk edebiyatı ürünleri; içerdikleri basit, canlı, somut dil ile ilgi çekici temaların birleşmesi sayesinde ikinci dil öğretiminde oldukça verimli bir malzeme oluşturur (Chen, 2014, s. 232).

Çocuklar, ana dili ve yabancı dil ediniminde uygun koşullar sağlandığında hızlı ve verimli öğreniciler olabilir. Burada üzerinde durulması gereken nokta, çocukların gerçek iletişim durumlarına mümkün olduğunca yakın, anlamlı ve eğlenceli içeriklere maruz bırakılmalarıdır. Çocuklar ikinci bir dili edinirken komutlarla öğrenmektense aktif katılımlı öğrenmeyi tercih ederler. Bu bağlamda hikâyeler ve hikâye kitapları ile çocuklara yabancı dil öğretim süreçlerini eğlenceli ve anlamlı hâle getirmek mümkündür.

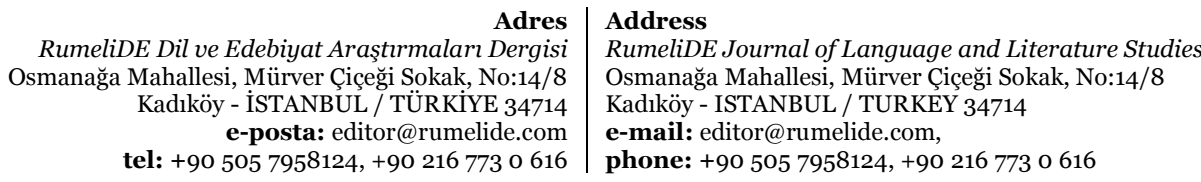


Çalışmamızda çocuklara yönelik anlatılar bağlamında "hikâye" sözcüğü tercih edilmiştir. Hikâye, Türkçe Sözlük’te şöyle tanımlanmaktadır: "1. Bir olayın sözlü veya yazılı olarak anlatılması. (...) 3. Ed. Gerçek veya tasarlanmış olayları anlatan düzyazı türü, öykü” (TDK, 2011).

Yukarıdaki tanımda hikâyenin karşıllğı olarak öykünün de verildiği görülmektedir. Hikâye kavramının içinde güçlü bir "anlatı" anlamı bulunur. Bu konuda M. Kayhan Özgül hikâyenin Arapça taklit etmek, bir metnin kopyasını çıkarmak, aynen nakletmek anlamlarına gelen "hakeve" kökünden geldiğini vurgulayarak şöyle der:

"Hikâye (story, geschichte) kelimesi sanki bir formun adı imiş gibi gösterilse de aslında 'narration' ve ‘fiction' özelliği taşıdığı için tahkiyeli diye anılan metinlerin müşterek adı 'hikâye'dir. Hikâye kelimesi; destandan masala, fikradan menkabeye, romandan tiyatroya hatta senaryoya varana kadar bütün tahkiyeli metinleri kucaklar." (Özgül, 2000, s. 33).

Hikâye anlatımı oldukça uzun zamandır güçlü bir iletişim şeklidir. Bu yönüyle anlatı, deneyimleri organize etmenin yaygın bir yolu olarak kabul edilir. Bu sebeple çok küçük çocuklar bile bir anlatıdan ne bekleyeceklerini ve buna nasıl karşllı vereceklerini bilebilirler (Howe ve Johnson 1992, 3'ten aktaran Gomez, 2010, s. 32). İnsanlar dili kullanmaya başladığından bu yana hikâye anlatımı her türlü bilgiyi aktarmada kullanılmıştır. Bugün hikâye kitaplarının ve hikâye anlatıcılığının gücü iyi öğretmenler tarafından bilinir. Hikâye kullanımı özellikle ilkokul çă̆ındaki çocukların müfredatlarında etkili görülmekle birlikte hikâye anlatmanın ve dinlemenin büyüsü yaşam boyunca devam eder.

Dünyada çocuklara yabancı dil öğretimi çalışmalarının daha gelişmiş olduğu görülmektedir. Bu bağlamda hikâyelerin ve hikâye kitaplarının çocuklara dil öğretiminde nasıl kullanılabileceğine dair kaynaklar mevcuttur. Oysa Türkçede bu konuda yapılan çalışmaların sınırlılı̆̆ı alan yazında büyük bir boşluk yaratmıştır. Bu boşluk uygulamada da eksiklikler doğurmaktadır. Bu çalışmada uluslararası alan yazından nitel araştırma yöntemlerinden literatür taramasına dayalı olarak toplanan veriler eleştirel bir değerlendirmeye tabi tutularak derleme çalışması yapılmıştır. Bu yöntemle toplanan veriler ışığında şu soruların cevapları aranmaktadır:

1.Çocuklara yabancı dil olarak Türkçe öğretiminde hikâyeleri kullanmanın etkisi nedir?

2.Çocuklara yabancı dil olarak Türkçe öğretiminde hikâyeler seçilirken ve sınıfa sunulurken nelere dikkat edilmelidir?

\section{Çocuklara yabancı dil öğretiminde neden hikâyeler kullanılmalı?}

Hikâyelerin ve hikâye anlatıcılığının yabancı dil sınıflarında özel bir pedagojik değeri vardır. Çünkü hikâyeler inandırıcı, hatırlanabilir ve eğlencelidir. Hikâyelerin inandırıcılıkları, gerçek ve güvenilir bilgi kaynağı olan insana veya insanın etrafındaki deneyimlere dayanmasından kaynaklanır. Hikâyeler hatırlanabilirdir çünkü okuyucu, karakterlerin eylemlerine ve niyetlerine dâhil olur. Bu sayede okuyucu hem anlamı keşfeder hem de onu oluşturur. Öte yandan hikâyeler kişisel gelişim ve dönüşüme destek verir. Hikâyelerdeki karakterlerin dönüşüm ve başarı öyküleri yabancı dil sınıfındaki öğrenciler için motive edici ve yol gösterici olabilmektedir (Rossister, 2002, s. 3).

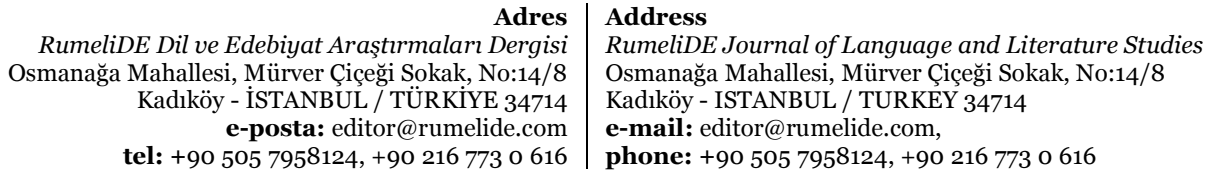

RumeliDE Dil ve Edebiyat Araştırmaları Dergisi -posta: editor@rumelide.com tel: +90 505 7958124, +90 2167730616 
Hikâyelerin ve hikâye kitaplarının çocuklara yalnızca ana dilde değil yabancı dil edindirmede de oldukça etkili olduğu konusunda araştırmacılar çeşitli görüşler ortaya koymuştur. Ellis ve Brewster (2014, s. 6-7) çocuklara yabancı dil öğretiminde hikâye kullanımını şöyle gerekçelendirir:

1. Çocuklar ana dillerinde hikâye dinlemekten zevk alır. Yabancı dil öğrenirken de hikâye dinlemek isteyeceklerdir.

2. Hikâyeler eğlenceli ve motive edici olmanın yanı sıra başka kültürlere karşı olumlu farkındalık yaratır.

3.Hikâyeler, çocuğun kahramanlarla özdeşleşme veya çizimleri (illüstrasyonları) yorumlama gibi yollarla anlatıya kişisel olarak dahil olmasını sağlar. Bu durum çocuğun hayal gücünü kullanmasını destekler. Öte yandan gerçek yaşam ile hayal dünyası arasında kurdukları bağlar çocuğun ev ve okul yaşantısındaki bağları güçlendirir.

4. Sınıf ortamında bir toplulukla hikâye dinlemek çocuğun öz güvenini ve sosyal gelişimini destekler.

5. Çocuklar hikâyeleri tekrar tekrar okumaktan ve dinlemekten oldukça hoşlanırlar. Bu tekrarlar hikâyelerde yer alan dil unsurlarının pekiştirilmesini ve yeni dil unsurlarının öğrenilmesini kolaylaştırır. Hikâyeler belirli dil unsurlarının tekrarlarını taşıdıkları için oldukça kalıcı öğrenmeler gerçekleşebilir.

6. Çocuklar hikâye dinleyerek ritim, telaffuz, tonlama gibi dile dair konularda farkındalık geliştirirler.

7. Hikâye kitapları çocukların dinleme becerisinin geliştirilmesinde özel bir öneme sahiptir. Çeşitli ses efektlerinin kullanıldığı ve kaliteli çizimlerle desteklenen hikâye anlatma etkinlikleri dinleme becerisini destekler.

8. Hikâyelerde kullanılan evrensel temalar, çocukların basit diyalogların ötesine geçerek dünyaya dair konular üzerine düşünmelerini sağladığı için oldukça geliştiricidir.

9. Hikâyelerin ve hikâye kitaplarının çeşitliliği çocukların sahip olduğu zekâ türlerinin çeşitliliğini karşılamakta oldukça başarılıdır.

Shin ve Crandall (2014, s. 214) çocuklara yabancı dil öğretiminde hikâyeleri kullanmanın yeni dil yapılarıyla sözcükleri aktarmanın eğlenceli ve heyecanlı bir yolu olduğunu vurgularlar. Araştırmacılar şu noktalara dikkat çekerler:

1. Bütün kültürlerde hikâye ve hikâye anlatıcllğ̆ı mevcuttur. Dolayısıyla hikâye çocukların ilgisini çekecek gerçek bir iletişim şeklidir.

2. Hikâyeler ve hikâye anlatıcılığı başka kültürleri tanımak ve bunlara dair değer ve kavramları deneyimlemek için güçlü araçlardır.

3. Çocukların dikkat sürelerinin düşüklüğü göz önünde bulundurulduğunda hikâye kullanımı dil öğrenme sürecinin gizlendiği eğlenceli bir aktivite olması yönüyle değerlidir.

\begin{tabular}{|c|c|}
\hline & \\
\hline debiyat & Studie \\
\hline $\mathrm{Mah}$ & Mahallesi, Mürver Çiçeği Sokak, No:14/8 \\
\hline Kadıköy - İ & STANBUL / TURKEY 34714 \\
\hline $\begin{array}{r}\text { e-posta: editor@rumelide.com } \\
\text { tel: }+905057958124,+902167730616\end{array}$ & $\begin{array}{l}\text { e-mail: editor@rumelide.com, } \\
\text { phone: +90 505 7958124, +90 } 216773 \text { o } 616\end{array}$ \\
\hline
\end{tabular}


4. Hikâyeler çocukların eleştirel düşünme becerilerini geliştirmede etkilidir. Hikâye hakkında yapılan konuşmalar ve sorular kendi fikirlerini oluşturmada çocuklar için destekleyicidir.

\section{Doğru hikâye seçimi}

Çocuklara yabancı dil olarak Türkçe öğretiminde hikâye kullanmaya karar veren bir öğretmenin dikkat etmesi gereken ilk nokta doğru hikâyeyi veya hikâye kitabını seçmek olmalıdır. Her hikâye her dil sınıfının ihtiyaçlarına cevap vermeyebilir. Bu sebeple hikâyenin çeşitli ölçütlerle ön değerlendirmeye alınması önemlidir.

Hikâyeler, öğrencilerin yaşına ve dil düzeyine bağlı olarak seçilmelidir. Dahası, öğretmenin odaklanmak istediği fikirleri aktarması için hikâye seçiminde belirli bir amaç olmalıdır. Cevaplanması gereken bir diğer önemli soru, çocuklar için basitleştirilmiş hikâye kitaplarının mı yoksa özgün hikâye kitaplarının mı kullanılacağıdır. Özgün hikâye kitapları gerçek dil örnekleriyle doludur ancak basitleştirilmiş hikâyeler ilköğretim öğrencileri için daha kolay olabilmektedir. Bu noktada sınıfın ihtiyaçları ve öğretmenin hikâyeyi adapte etme becerisi son derece belirleyicidir. Her ikisinin de kullanılabileceği durumlar vardır (Gomez,2010, s.38-39).

“Dil sınıflarında kullanılacak iyi hikâye nedir?” sorusunun cevabını Cameron (2011, s. 166-167) çocukların ilgisini çeken bir olay örgüsüne ve karakterlere sahip hikâye olarak verir. Buna göre çocukların hikâyede yaratılan hayal dünyasına girebilmeleri, karakterler ve olaylarla empati kurabilmeleri gereklidir. Bu sebeple çocukların hayal etmelerini sağlayacak detayları içeren hikâyeler daha başarılıdır. Kutuplarda yaşayan çocuklara çölde geçen bir hikâye anlatılacaksa hayal gücünü destekleyici çokça detay verilmelidir. Öte yandan bir hikâyede geçebilecek "kaplanın mutfakta çay içmesi” metaforundaki gibi hayal dünyası ile gerçeklik arasında bağlantılar kurulmalıdır.

Ellis ve Brewster (2014, s. 18) doğru hikâyeyi veya hikâye kitabını seçerken öğretmenin aşağıdaki soruları sorması gerektiğini; bu soruların tamamına olmasa bile belirli bir bölümüne alınacak olumlu cevaplarla yola devam etmesi gerektiğini belirtir:

- Öğretmen hikâyeden hoşlandı mı ve coşkuyla anlatabilecek mi?

- Sınıftaki çocukların seveceği bir hikâye mi?

- Çocukların dikkatlerini çekebilecek ilginç bir hikâye mi?

- Hikâye doğru uzunlukta mı, parçalara bölünebiliyor mu?

- Çocukların ana dillerinden bildikleri bir hikâye mi? (Masal vb.)

- Fazla karmaşık olmayan net bir hikâye mi?

- Tekrarlayan dil bilgisi yapıları var mı?

- Kafiye ve ritim var mı?

- Yansıma sözcükler var mı?

- Gerilim, şaşkınlık ve mizah unsurları içeriyor mu?

\begin{tabular}{|c|c|}
\hline & \\
\hline & of \\
\hline $\begin{array}{r}\text { Adres } \\
\text { RumeliDE Dil ve Edebiyat Araşttrmalar Dergisi } \\
\text { Osmanağa Mahallesi, Mürver Ciceği Sokak, No:14/8 }\end{array}$ & $\mathrm{O}$ \\
\hline Kadıköy - I & 714 \\
\hline tel: +9050 & $\begin{array}{l}\text { editor@rumelide.com, } \\
\text { +90 505 7958124, +90 } 216773 \text { o } 616\end{array}$ \\
\hline
\end{tabular}


- Çocuğun hayal gücünü geliştirmeyi ve aktif katılımı teşvik ediyor mu?

- Evrensel temaları ele aliyor mu?

- Resimler yeterli büyüklükte mi ve güçlü bir görsel destek sunuyor mu?

Çocuklara yabancı dil olarak Türkçe öğretirken hikâye kullanımında çocuğun dil düzeyini ve kavramsal yeterlik düzeyini karşılayan materyali kullanmak başarııı getirir. Çocukların dil öğrendikleri sınıflarda sadece yaşları değil Türkçeyi öğrenmeye başlama yaşları, gördükleri öğrenimin kalitesi, hedef dile maruz kalma oranı, ilgi alanları gibi faktörler oldukça belirleyicidir. Öğretmenler çeşitli hikâye kitapları arasından seçim yapabilirler: Geleneksel hikâyeler, masalları, metin içermeyen resimli hikâye kitapları, mizahî hikâyeler gibi geniş bir yelpaze söz konusudur. Özgün hikâyeler kullanılacaksa bu hikâyelerin dil öğretimi için yazılmadığı göz önünde bulundurulmalıdır. Öte yandan özgün hikâyeler dil unsurları ve kavramlar açısından çeşitlilik barındırır. Özgün hikâyelerle çalışılırken kesin ölçütler kullanılamaz. Ancak bu hikâyelerin yaşa ve seviyeye uyarlanması için çeşitli ölçütlerden söz edilebilir.

Sınıfta kullanılacak özgün hikâyeler uyarlanırken gereğinden fazla değişiklik ve basitleştirme yapılırsa hikâye büyüsünü kaybedebilir. Belirli sınırlar dâhilinde yapılacak uyarlamalar çocuğun seviyesinin ne çok üstünde ne de altında uyarlamalar elde edilmesini sağlayabilir.

Söz varlığını kontrol edin: Bilinmeyen sözcükler çok fazlaysa bilinen karşılıkları ile değiştirilebilir.

Söz Varlığı Deyimleri kontrol edin: Daha açık ifade edilmesi gereken deyimler basitleştirilebilir.

Anlatım açıklı̆̆ını kontrol edin.

Zamanları kontrol edin: Çok fazla zaman varsa basitleştirilebilir. Geçmiş zaman kullanmaktan çekinmemek gerekir. Çocuk zaten hikâyenin geçmiş zamanda kullanıldığını

Dil Bilgisi bilir

Yapıların kullanımını kontrol edin.

Söz dizimini kontrol edin.

Cümlelerin uzunluğunu ve karmaşıklığını kontrol edin.

Fikirlerin birbirleriyle ilişkisini kontrol edin.

Fikirler $\quad$ Fikirlerin sayısını kontrol edin. Bazı karakter ve olayları hikâyeyi kısaltmak için dışarıda birakın.

Tablo 1. Sınıfta hikâye kullanım ölçütleri (Ellis ve Brewster, 2014, s.17'den uyarlanmıştır.).

\section{Hikâye sınıfta nasıl sunulmalı?}

Yüksek sesle hikâye okuma çocukların sözlü dil ile onu temsil eden yazı arasında bağlantı kurması açısından faydalıdır. Hikâye okuma çocuklara hedef dilde sözlü girdi sağlar; bunun yanında hedef dilin okuryazarlık becerilerine ulaşmada çocuk için köprü görevi görür. Hikâye okurken doğru çizimlerin desteğini almak da önemlidir. Resimli hikâye kitapları kullanılabilir. Resimlerle desteklenen hikâyeler akılda daha kalıcı olmaktadır (Gonzalez, 2010, s. 98-99).

Çocuklara yabancı dil olarak Türkçe öğretilen sınıflarda uygun hikâyenin seçilmesi kadar bunun sınıfta çocuğa nasıl sunulduğu da önemlidir. Bu noktada öğretmenin vermesi gereken çeşitli kararlar vardır: Hikâyenin okunarak mı yoksa hikâye anlatıcılığı yolu ile mi sunulacağına karar verilmelidir. Hikâye anlatıcılığı birtakım özel beceriler gerektiren bir yoldur. Ĕger hikâye okunacaksa öğretmen tarafından 
mı okunacağına yoksa kayıttan mı dinletileceğine karar verilmelidir. Öğretmenin hikâyeyi okuması öğrenci ile iletişime girmesini kolaylaştıracaktır. Kayıttan dinletmek ise hem farklı ses efektlerinin kullanılması hem de çocukların öğretmenin sesletiminin dışında farklı bir sesletim duymaları açısından yararlıdır.

Hikâye anlatılırken sınıfta rahat bir dinleme ortamının sağlanması önemlidir. Araştırmacılar rahat sınıf ortamının öğrenmeyi desteklediğini belirtmektedir (Gomez, 2010, s. 41). Çocuklara yabancı dil olarak Türkçe öğretiminde sınıfta hikâye anlatımı için hazırlık yapılırken çocuklardan çember şeklinde oturmalarını istemek, mümkünse yerde minderlerde oturmalarını sağlamak; daha paylaşımcı, rahatlatıcı ve eğlenceli bir dinleme ortamı sağlayacaktır. Ĕger hikâyeler sınıfta düzenli olarak kullanılıyorsa hikâye anlatma saatlerine özgü bir başlangıç müziği, kukla veya içinden hikâyenin çıktığı bir torba kullanılabilir. Böyle rutinler çocukların hızlıca konsantrasyonunu sağlar.

Çocuklar için yabancı dil sınıflarında hikâyenin kullanımında Cameron (2010, s. 174-175) üç aşamalı bir yöntem önermektedir: İlk aşamada hikâyeye dair bir görseli gösterip söz varlığının tahtaya yazılması ile beyin fırtınası yaratılır. Burada bilinmeyen birkaç sözcüğe de yer verilir. Hazırlık aşaması olarak kabul edilebilecek bu çalışmadan sonra çekirdek etkinlik olarak hikâye öğretmen tarafindan okunur veya dinletilir. İlk okumada öğretmen fazla müdahale etmeden sözü öyküye bırakıp ikinci okumada çeşitli duraksamalar ile anahtar kelimelere veya fikirlere dikkat çekebilir. Ardından gelen takip etkinlikleri çeşitlendirilebilir ve dil öğretimi için fazlaca olanak sunar. Anında takip etkinliği olarak çocuğun hikâyenin içinden sevdiği beş sözcüğü seçip çizmesi, daha sonra evde ebeveynleri ile paylaşması istenebilir. Diyalogların basitleştirilip öğrenciler tarafından canlandırılması, hikâyelerdeki cümleleri başka bağlamlarda kullanma, hikâyelerdeki karakterleri başka yerlere aktarma gibi etkinlikler kullanılabilir.

Çocuklara yabancı dil olarak Türkçe öğretiminde hikâye kullanımında sınıfa getirilen hikâye için üç aşamadan söz etmek mümkündür: Hazırlık (ön okuma), okuma ve okuma sonrası etkinlikler.

Hazırlık etkinlikleri önemlidir çünkü çocukları hikâyenin içeriği ile tanıştırır. Bu sayede çocukların hikâye ve kullanılan dil hakkında fikir sahibi olarak onu dinlemek için bir sebepleri olur. Hazırlık aşamasında öğretmenin hikâyedeki bilinmeyen sözcükleri tespit etmesi ve çocuğun bunların belirli bir bölümü ile karşılaşmasını sağlaması gerekir. Bu yolla hikâyenin çocuk için tamamen anlaşılmaz olması önlenmiş olur. Öte yandan resimler bu noktada çok işlevseldir. Doğru ve kaliteli çizimler çocuğun her sözcüğün anlamını bilmese bile söylemin yapısını çözmesine yardımcı olur. Hikâye hakkında bir görsel göstermek, hikâyede geçen sözcükleri tahtaya yazmak, hikâye kitabının kapağını gösterip çocuklardan tahminlerde bulunmalarını istemek gibi yollar izlenebilir. Hikâyenin zor olduğu düşünülüyorsa ana dilinde çok kısa bir özet yapılabilir.

Okuma aşamasında öğretmenin anlatma/okuma becerileri önem kazanır. Birden çok okuma veya anlatma yapmak mümkündür. Çünkü çocuklar tekrarı sever. Çocukların düşük konsantrasyon süreleri de göz önünde bulundurularak aktif dinleyiciler olabilmeleri için karakterleri numaralandırmak, en sevdikleri karakteri seçtirmek, hikâyede geçen bir tekerlemeyi veya kafiyeli söz grubunu tekrar ettirmek gibi yöntemler seçilebilir. Okuma aşamasında okunan metin ile resimler arasında ilişki kurmak önemli olduğundan çocuğun kitabın resimlerini rahatça görebilmesi gereklidir. Bu amaçla büyük boyutlarda hikâye kitapları kullanılabilir. Okuma sırasında çocuğun tahmin becerilerini kullanmak da önemlidir. Bu sayede hikâyenin çocuk tarafından anlaşılıp anlaşılmadığı kontrol edilir.

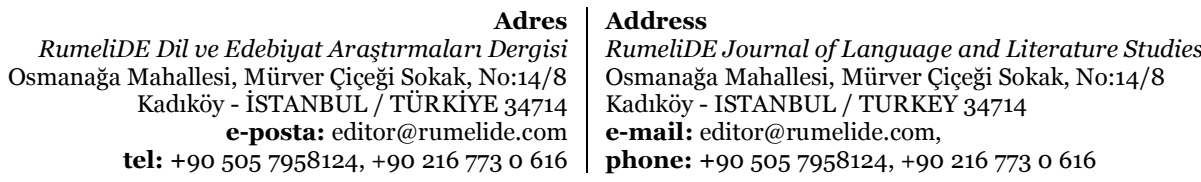


Öte yandan çocuğun önceki bilgilerini aktifleştirip o sırada okunan hikâye üzerine derinleşmesi sağlanır.

Okuma sonrası etkinlikler ise çocuğa dile dair unsurların aktarılmasında çeşitli firsatlar sunar: Hikâyedeki bir kahramanı, sevdikleri bir sahneyi veya okunan kitabın kapağını yeniden çizmeleri istenebilir. Bu tip etkinlikler çizmeyi ve boyamayı seven çocuklar için ilgi çekicidir. Hikâyenin sözlü ve yazılı olarak yeniden üretimini destekleyecek etkinlikler verimlidir. Hikâyedeki resimlerle ilgili birer cümle söylemleri veya yazmaları istenebilir. Hikâyedeki sorun ya da çatışma çocuğun yaşadığı gerçek dünyaya (eve, mahalleye) aktarılıp sözlü üretim yaptırllabilir. Rol yapma etkinlikleri hikâyedeki bir karakteri veya olayı canlandırma bağlamında kullanılabilir. Yazılı üretim yaptırmak da önemlidir.

\section{Sonuç}

Çocuklar eğlenceli ve tanıdık etkinliklerle karşılaşırlarsa oldukça başarılı dil öğrenicileri olabilmektedir. Araştırmalar göstermektedir ki kaliteli çocuk edebiyatı ürünleri hem ikinci dil öğretiminde hem de çocuğun başka kültürlere karşı olumlu tutum geliştirmesinde oldukça etkilidir. Çocuklara yabancı dil olarak Türkçe öğretiminde hikâyeler; eğlenceli, ilginç ve akılda kalıı malzemeler olmaları yönüyle oldukça kullanışlıdır. Hikâyelerin kullanımı ile çocuklar dili kavramsallaştırabilir, dilin anlam ve işlevlerini tanıyabilir. Çocuğun sınıfta kendini güvende ve iyi hissetmesini sağlayan hikâye etkinlikleri bu yönüyle ikinci dil edinimini kolaylaştırıcıdır. Çocuklara yabancı dil olarak Türkçe öğretiminde hikâyeleri ve hikâye kitaplarını dil öğretim araçlarına dönüştürmek öğretmenin çeşitli bilgi ve becerileri kullanması ile mümkündür. Öğretmen, sınıfta kullanılacak hikâye kitaplarının kalitesini ve dil öğretiminde kullanılma potansiyellerini değerlendirecek ölçütleri bilmelidir. Sınıfa getirilecek hikâyenin belirlenmesinde öğrencinin ilgi alanları, yaş, kavramsal hazır bulunuşluk ve dile dair önceki bilgiler mutlaka göz önünde bulundurulmalıdır. Ayrıca hikâyenin söz varlı̆̆ı, dil bilgisi ve barındırdığı fikirler açısından da uygun olup olmadığı kontrol edilmeli; gerekiyorsa bunlara çeşitli müdahaleler yapılmalıdır. Kullanılacak hikâyenin veya hikâye kitabının mutlaka yeterli büyüklükte ve kalitede resimlere sahip olması gerekir. Düşük kaliteli resimler, çocuğun metni görsellerle anlamlandırmasına izin vermeyeceği ve ilgisini yeterince çekmeyeceği için etkinliğin başarısız olmasina sebep olacaktır.

Çocuklara yabancı dil olarak Türkçe öğretilen sınıflarda hikâye kullanılan dersler iyi organize edilirse öğrencinin ilgisini çekecek ve dile dair merakını artıracaktır. Hikâyenin sınıfta öğretmen tarafından okunarak mı yoksa hikâye anlatıcılığı yoluyla mı sunulacağı da öğretmenin vermesi gereken kararlardandır. Bu bağlamda öğretmenin hikâyeyi okumak ile onu anlatmak arasında bir tercih yaptıktan sonra hazırlık, okuma ve okuma sonrası etkinliklerini planlaması gereklidir. Bu etkinlikler dinleme, okuma, konuşma, yazma, telaffuz, dil bilgisi ve kelime öğretimi alanlarında yoğunlaşır. Çocuklara yabancı dil olarak Türkçe öğretimi sahasında materyal üretenlerin, akademisyenlerin ve sahada çalışan eğitimcilerin yeterli teorik altyapıya sahip olduğunda daha verimli ürünler ortaya konacağı bir gerçektir.

\section{Kaynakça}

Akalın Ş. H. vd. (2011). Türkçe Sözlük. Ankara: Türk Dil Kurumu.

Barın, E. (2004). Yabancılara Türkçe Öğretiminde İlkeler. Hacettepe Üniversitesi Türkiyat Araştırmaları Dergisi, (1), 19-30. Erişim: 28 Aralık 2020 https://dergipark.org.tr/tr/pub/turkiyat/issue/1666o/329608.

Cameron, L. (2001). Teaching Languages to Young Learners. Cambridge: Cambridge University Press.

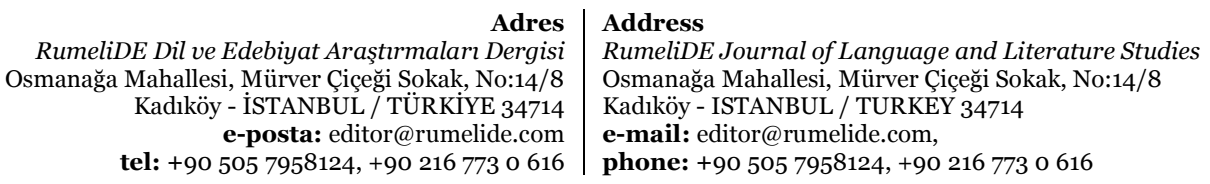


Chen, M. L. (2014). Teaching English as a Foreign Language through Literature. Theory and Practice in Language Studies, Vol. 4, No. 2, s. 232-236.

Davies, A. (2007). Storytelling in the Classroom, Enhancing Traditional Oral Skills for Teachers and Pupils. London: SAGE Publications.

Ellis, G., Brewster, J. (2014). Tell it again: The New Storytelling Handbook For Primary Teachers. United Kingdom: British Council.

Gómez, A. B. (2010). How to Use Tales for The Teaching of Vocabulary and Grammar in a Primary Education English Class. Resla, 23, s. 31-52.

González, N. I. P. (2010). Teaching English through Stories: A Meaningful and Fun Way for Children to Learn the Language. Profile Issues in Teachers` Professional Development, 12(1), 95-106. Erişim: 17 Mart 17 2021, http://www.scielo.org.co/scielo.php?script=sci_arttext\&pid=S165707902010000100007\&lng= en\&tlng=en.

Kurt, E. (2020). Çocuklara Yabancı Dil Olarak Türkçe Öğretimi (6-11 ve 12-15 Yaş). Adana: Karahan.

Özgül, M. K. (2000). Hikâyenin Romanı. Hece, Türk Öykücülüğü Özel Sayısı, 46/47, s.31-39.

Rossiter, M. (2002). Narrative and Stories in Adult Teaching and Learning. Columbus, OH: ERIC Clearinghouse on Adult Career and Vocational Education. (ERIC Document Reproduction Service No. EDO CE 02 214).

Shin, J. K., Crandall, J. (2014). Teaching Young Learners English from Theory to Practice. Boston: National Geographic Learning / Heinle Cengage Learning.

Zigárdyová, L. (2006). Using Stories in Teaching English to Young Learners (Yayımlanmamış Bitirme Tezi). Masaryk University, Faculty Of Education, Brno. 